\title{
Plasma Galectin-9 Concentrations in Normal and Diseased Condition
}

\author{
Toshiro Nikia,b Koji Fujitac Hugo Rosen ${ }^{\mathrm{d}}$ Mitsuomi Hirashimab,c

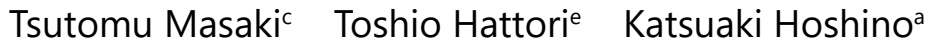

${ }^{a}$ Department of Immunology, Faculty of Medicine, Kagawa University, Kita-gun, Kagawa, ${ }^{\mathrm{b}} \mathrm{GalPharma}$ Co., Ltd., Takamatsu-shi, Kagawa, 'Department of Gastroenterology and Neurology, Faculty of Medicine, Kagawa University, Kita-gun, Kagawa, Japan, ${ }^{d}$ Department of Medicine, Keck School of Medicine, University of Southern California, Los Angeles, CA, USA, eGraduate School of Health Science, Kibi International University, Takahashi-shi, Okayama, Japan

\section{Key Words}

Galectin-9 • Immune checkpoint • Degradation • ELISA

\begin{abstract}
Background/Aims: Galectin-9 is a soluble immune modulator with versatile functions, including a role as an immune checkpoint molecule. Therefore, the amount of galectin-9 in the blood may reflect an individual's immunological balance. Many studies have conducted galectin-9 measurements; however, the reported galectin-9 concentration in the blood varies greatly, even within healthy controls. This study investigates the variation between the reported and actual concentrations of galectin-9. Methods: A GalPharma ELISA and an R\&D Systems ELISA kit were directly compared using the same set of plasma and a series of recombinant galectins, including degraded galectin-9. Furthermore, galectin-9 in plasma was concentrated using anti-galectin- 9 antibody-conjugated beads, and subjected to western blotting to estimate the quantity and integrity of galectin- 9 and assess the consistency of ELISA measurements. Results: The R\&D Systems' ELISA indicated a 50-fold higher median concentration of plasma galectin-9 than that indicated by the GalPharma ELISA. This variation is due to aberrantly enhanced reactivity of the R\&D Systems' ELISA to degraded galectin-9 present in small quantities in the plasma. The GalPharma ELISA could detect only intact galectin- 9 and its results correlated well with the plasma galectin- 9 level obtained by western blotting. Conclusion: ELISA kits from R\&D Systems reacts aberrantly higher against degraded galectin-9 than the intact galectin-9. Therefore, the existence of a small amount of degraded galectin- 9 in a test sample hinders the quantification. As galectin- 9 is a fragile protein, this is a serious concern when using this kit. Based on quantifications from the GalPharma ELISA, the median ( $25^{\text {th }}-75^{\text {th }}$ percentiles) galectin- 9 concentration in healthy subjects in the current study cohort was calculated as $110 \mathrm{pg} / \mathrm{mL}(67-154 \mathrm{pg} / \mathrm{mL})$.
\end{abstract}




\section{Introduction}

Galectin-9 (Gal-9) is a $\beta$-galactoside-binding animal lectin of the galectin family that is expressed ubiquitously in tissues and cells, with particular abundance in the immune and epithelial cells of gastrointestinal tracts. Gal-9 suppresses T helper type 1 (Th1) and Th17 cells and activates regulatory $\mathrm{T}$ (Treg) cells both in vitro and in vivo, which explains the antiinflammatory effects of Gal-9 administration in autoimmune and allergic animal models [1]. Recently, Gal-9 was annotated as an immune checkpoint molecule, together with its receptor T-cell immunoglobulin and mucin domain 3 (Tim-3) [2]. Recent research has focused on the strategy to neutralize this lectin in an attempt to reactivate immune cells to fight against cancers and/or infections. Contrary to this goal, Gal-9 demonstrates anti-cancer effects in several tumor-bearing mouse models by either inducing apoptosis of cancer cells or activating immune cells such as dendritic cells, NK cells, and cytotoxic T cells [3-6]. Several retrospective studies clarified the positive correlations between Gal-9 expression in cancer tissues and improved patient prognosis in various cancer types [7]. These observations are inconsistent with the well documented immune suppressive function of Gal-9 and have revealed that Gal-9 biology is complex and poorly understood.

Because Gal-9 is a multi-functional immune modulator, and the only known soluble immune checkpoint molecule, its concentration in the blood may reflect an individual's immune balance and could be a useful clinical biomarker. Using a GalPharma (GalP) ELISA, we have reported that the concentration of Gal-9 in the blood fluctuates rapidly, reflecting the pathological conditions of patients with various diseases [8-17]. Similar disease-related fluctuations have been reported using both independently developed and commercially produced ELISAs [18-31]. When the reported Gal-9 concentrations were compared, a large divergence was observed in the results, even within healthy control groups, with values ranging from 0 to $26,560 \mathrm{pg} / \mathrm{mL}$. It is unlikely that these variations are the result of sample set differences such as participant race, use of plasma vs. serum, collection methods, or statistical analysis methods. This study examined the factors that might influence the variations observed in Gal-9 values reported in the literature and aimed to provide an accurate measurement of the concentration of functional Gal-9 in the blood.

\section{Materials and Methods}

\section{Ethics Statement}

The study protocol was approved by the Institutional Review Boards at the University of Colorado Health Sciences Center, Denver and the Oregon Health Sciences University, Portland. Both written and oral consent was obtained from participants before samples were collected.

\section{Preparation of galectins}

Gal-1, Gal-3, Gal-4, Gal-7, Gal-8, Gal-9, Gal-9(0), Gal-9(N), and Gal-9(C) were prepared as previously described [32-34]. Gal-9 represents wild-type Gal-9 and the S-type splicing variant was prepared. Gal-2 (Gene Bank accession no: CR541972.1) and Gal-10 (Gene Bank accession no: BC119711.1) were synthesized in open reading frames containing BamHI and EcoRI recognition sequences at the 5' and 3' ends, respectively, and cloned into the BamHI-EcoRI sites of the pGEX-4T-2 plasmid (GE Healthcare, Buckingham shire, England, UK). The glutathione S-transferase fusion proteins for Gal-2 and Gal-10 were produced in E. coli BL21, purified with a glutathione-Sepharose column (GE Healthcare), and eluted by digestion with thrombin (GE Healthcare). All the galectins were dialyzed against Dulbecco's phosphate-buffered saline without calcium and magnesium (PBS) and cleared of endotoxin using Cellufine ETclean L (Chisso, Tokyo, Japan).

ELISA

Gal-9 concentration was quantified using ELISA kits from R\&D Systems (Minneapolis, MN, USA), according to the manufacturer's instruction, or the GalP ELISA system described previously [9, 35]. 


\section{Cellular Physiology Cell Physiol Biochem 2018;50:1856-1868 \begin{tabular}{l|l|l} 
and Biochemistry Published online: 3 November 2018 & $\begin{array}{l}\text { (c) } 2018 \text { The Author(s). Published by S. Karger AG, Basel } \\
\text { www.karger.com/cpb }\end{array}$ \\
\hline
\end{tabular}

\section{Degradation of Gal-9 by elastase}

Highly purified wild-type Gal-9 S-type variant $(66 \mu \mathrm{g} / \mathrm{mL})$ was incubated with $0.96 \mu \mathrm{g} / \mathrm{mL}$ of elastase (Sigma-Aldrich, St. Louis, MO, USA) in a buffer containing $100 \mathrm{mM}$ Tris- $\mathrm{HCl}$ (pH8.0) and $1 \mathrm{mM} \mathrm{CaCl}_{2}$ at $37^{\circ} \mathrm{C}$. At the indicated time point, $5 \mu \mathrm{L}$ of the reaction was transferred into a micro tube containing $15 \mu \mathrm{L}$ of Complete Protease Inhibitor Cocktail (Roche Diagnostics, Rotkreuz, Zug, Switzerland), then subjected to SDS-PAGE and ELISA.

\section{Detection of plasma Gal-9 by western blotting}

Anti-Gal-9(N) polyclonal antibody was produced by immunizing rabbits (Japanese White) with recombinant Gal-9(N) and purified from the rabbit serum with an affinity column prepared by binding the antigen to a HiTrap NHS-activated column (GE Healthcare). After purity and titer assurance, the antibody was then conjugated to a fresh HiTrap NHS-activated column. The resulting antibody-bound resin was removed and suspended in Binding buffer (PBS containing $2 \mathrm{mM}$ EDTA, 0.1\% sodium azide, and 2 x Complete Protease Inhibitor Cocktail). Plasma $(150 \mu \mathrm{L})$ was diluted with Binding buffer $(130 \mu \mathrm{L})$ then mixed with a $25 \%$ slurry of anti-Gal-9(N) antibody-conjugated resin in a spin column $(20 \mu \mathrm{L})(\mathrm{MoBiTec}$, Lotzestrasse, Göttingen, Germany). When indicated, recombinant Gal-9(0) and Gal-9(N) was added at 225 pg each. The reaction mixture was incubated for $4 \mathrm{~h}$, while gently mixed on a rotator, at $4^{\circ} \mathrm{C}$. The unbound fraction was removed by washing the column twice with PBS containing $0.05 \%$ tween- 20 . Gal-9 left in the column was released by the addition of $14 \mu \mathrm{L}$ of SDS-PAGE sample buffer containing 4\% SDS, $8 \mathrm{M}$ urea and 10\% 2-mercaptoethanol. The samples were subjected to SDS-PAGE, transferred to an Immobilon PVDF membrane (Merck, Frankfurter Strasse, Darmstadt, Germany), and assessed using the antibodies antihuman Gal-9 mouse monoclonal antibody (9S2-1, GalPharma, Takamatsu, Kagawa, Japan) with anti-mouse IgG horse-radish peroxidase conjugate (BioLegend, San Diego, CA, USA) for full-length Gal-9, and anti-Gal$9(\mathrm{~N})$ rabbit polyclonal antibody with anti-rabbit IgG horse-radish peroxidase conjugate (GE Healthcare) for degraded Gal-9. The signal was visualized by ECL prime (GE Healthcare) and a lumino-image analyzer LAS4010 (GE Healthcare). The digital data was processed using ImageJ (NIH Image, Bethesda, MD, USA) and the amount of Gal-9 was quantified using a standard constructed with recombinant Gal-9(0) and Gal-9(N).

\section{Presentation of data}

All the experiments were reproduced at least twice, and representative data was presented. For statistical analysis, the Mann-Whitney U-test and Spearman's rank correlation coefficient were used to assess the difference and correlation between a set of non-parametric data using Prism 5 (GraphPad software, La Jolla, CA, USA).

\section{Results}

Plasma Gal-9 quantities differ significantly based on the ELISA products employed

From publications assessing blood Gal-9 levels by ELISA, we selected reports that quantified Gal-9 concentration in a healthy control (HC) and summarized the data in Table 1. The Gal-9 concentration, either in plasma or serum, is widely varied even within the HC groups, and ranges from 0 to $26,560 \mathrm{pg} / \mathrm{mL}$. These large variations, however, can mostly be attributed to the ELISA kit employed, as much higher values were obtained with the R\&D Systems (RDS) as compared to the other 5 manufacturers' products (Fig. 1). The median Gal9 levels in HC were $5,061 \mathrm{pg} / \mathrm{mL}$ and $89 \mathrm{pg} / \mathrm{mL}$ from the RDS and the combined data from the other ELISAs respectively, which is a significant difference $(p=0.0003)$. On the other hand, the variation between the other 5 ELISA products was not significantly different. Specifically, the Gal-9 levels determined with the GalP ELISA was compared with those obtained with the other 4 ELISAs and did not show a significant difference, and the other combinations were invalid because of few examples.

Using plasma from patients with acute liver failure (ALF) and $\mathrm{HC}$, we directly compared the RDS and GalP ELISAs (Table 2 and 3 and Fig. 2A and 2B). ALF demonstrated significantly higher Gal-9 levels compared with HC in both ELISAs $(p<0.0001)$, hence the ALF-related increment of plasma Gal-9 that we published already using the GalP ELISA was reproduced 
Table 1. Reported Gal-9 concentration in the blood from healthy control (HC) and patients represented by Mean, Median, or Geometric mean. ELISA makers are abbreviated as follows. GalP = GalPharma, BGB = Blue Gene Biotech, RDS = R\&D Systems

\begin{tabular}{|c|c|c|c|c|c|c|c|}
\hline \multirow{2}{*}{ Disease } & \multirow{2}{*}{$\begin{array}{c}\text { Serum/ } \\
\text { Plasma }\end{array}$} & \multicolumn{3}{|c|}{ Gal-9 (pg/mL) } & \multirow{2}{*}{$\begin{array}{l}\text { ELISA } \\
\text { maker }\end{array}$} & \multirow{2}{*}{ Comments } & \multirow{2}{*}{ Ref } \\
\hline & & $\mathrm{HC}$ & Patient & Stat. & & & \\
\hline Chronic HCV infection & $\mathrm{P}$ & 112 & 1,276 & Mean & GalP & \multirow{5}{*}{ Values are read from the figure } & 9 \\
\hline Acute HIV-1 infection & $\mathrm{P}$ & 46 & 4,490 & Mean & GalP & & 10 \\
\hline Dengue fever & $\mathrm{P}$ & 196 & 1,407 & Median & GalP & & 11 \\
\hline Chronic HIV-1 infection & $\mathrm{P}$ & 54 & 326 & Median & GalP & & 12 \\
\hline Influenza infection & $\mathrm{P}$ & 14 & 184 & Mean & GalP & & 13 \\
\hline Acute liver failure & $\mathrm{P}$ & 80 & 350 & Mean & GalP & \multirow{2}{*}{$\begin{array}{c}\text { Values are read from the figure } \\
\text { HC: uncomplicated malaria after } \\
\text { mitigation }\end{array}$} & 14 \\
\hline Malaria infection & $\mathrm{P}$ & 243 & 923 & Median & GalP & & 15 \\
\hline Chronic HCV infection & $\mathrm{S}$ & 0 & 146 & Median & GalP & \multirow{4}{*}{ Values are read from the figure } & 16 \\
\hline Pulmonary tuberculosis & $\mathrm{P}$ & 14 & 172 & Median & GalP & & 17 \\
\hline HIV-1 infection & $\mathrm{P}$ & 160 & 1,000 & Median & Uscn & & 18 \\
\hline Endometriosis & $\mathrm{S}$ & 98 & 780 & Mean & $\mathrm{BGB}$ & & 19 \\
\hline Pregnancy & $\mathrm{S}$ & 110 & 1,980 & Median & AMS & $\begin{array}{l}\text { Non-pregnant vs 3rd trimester } \\
\text { Values are read from the figure }\end{array}$ & 20 \\
\hline Spontaneous abortion & $\mathrm{S}$ & 372 & 611 & Mean & AMS & HC: Non-pregnant & 21 \\
\hline Acute myeloid leukemia & $\mathrm{S}$ & 22 & 392 & Mean & Kamiya & & 22 \\
\hline Juvenile dermatomyositis & $\mathrm{P}$ & 6,711 & 32,133 & Median & RDS & & 23 \\
\hline Atopic dermatitis & $\mathrm{S}$ & 2,100 & 3,190 & Mean & RDS & & 24 \\
\hline Coronary artery disease & $\mathrm{S}$ & 3,566 & 3,284 & Mean & RDS & & 25 \\
\hline Dengue fever & $\mathrm{S}$ & 5,061 & 10,287 & Median & RDS & & 26 \\
\hline Atherosclerotic stroke & $\mathrm{S}$ & 6,490 & 7,230 & $\begin{array}{l}\text { Geo- } \\
\text { mean }\end{array}$ & RDS & & 27 \\
\hline Multiple sclerosis & $\mathrm{P}$ & 26,560 & 37,110 & Mean & RDS & & 28 \\
\hline Systemic sclerosis & $\mathrm{S}$ & 2,200 & 3,300 & Median & RDS & & 29 \\
\hline
\end{tabular}

Fig. 1. Blood Gal-9 concentration determined by RDS ELISA compared to that determined by 5 other products. Gal- 9 concentration $(\mathrm{pg} / \mathrm{mL})$ in serum or plasma from Healthy Controls (HC), expressed either as the median or mean, extracted from 21 publications and divided into two groups based on the manufacturer; R\&D Systems $(n=7)$ or the other 5 manufacturers ( $n=14$ ). The other manufacturers include Uscn, Blue Gene Biotech, AMS, Kamiya, and GalP. P -value was calculated using the two tailed Mann-Whitney U-test.

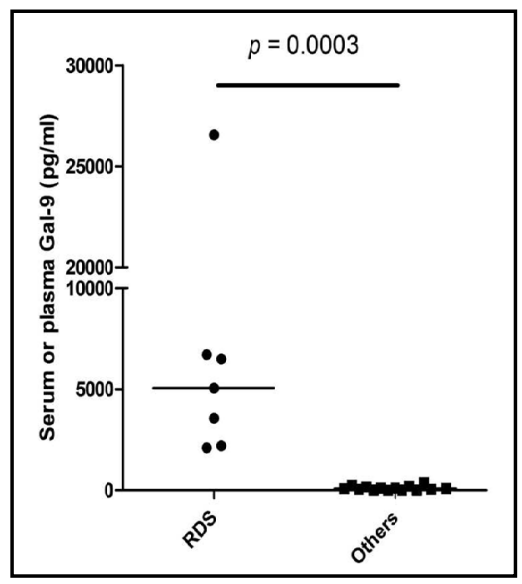

using the RDS ELISA. However, the actual Gal-9 values were different between the two kits, with the median values (pg/mL) of ALF vs $\mathrm{HC}$ as 23, 049 and 5, 355 respectively when determined with RDS ELISA and 426 and 110 respectively when determined with GalP ELISA. RDS ELISA indicated Gal-9 levels 54-fold higher in ALF and 49-fold higher in HC when compared to those obtained with GalP, which confirmed the hypothesis that RDS ELISA would obtain higher Gal-9 values. Fig. 2C examined the correlation of both measurements. They are correlated, though the correlation is not very strong (ALF: $r=0.5632, n=23, p=$ 0.0051; HC: $r=0.5445, n=17, p=0.0238$ ).

\section{Characterization analysis of RDS and GalP ELISAs}

Quantification by ELISA is affected by the purity and integrity of the Gal- 9 standard used to generate the calibration curve. When degradation occurs in standard Gal-9, it may shift the calibration curve and result in an overestimation of the quantity of Gal-9 in the test samples. As shown in Fig. 3A, Gal-9 consists of carbohydrate-recognition domains at the $\mathrm{N}$-terminus and $\mathrm{C}$-terminus with a linker peptide in between. Since Gal-9 is a fragile protein, and degradation starts at the linker peptide, the prepared Gal-9 samples may contain the 
Table 2. Head-to-head comparison of RDS and GalP ELISAs with ALF patient plasma

\begin{tabular}{lcccc}
\hline & \multicolumn{2}{c}{ RDS ELISA } & \multicolumn{2}{c}{ GalP ELISA } \\
Specimen & $\begin{array}{c}\text { Plasma Gal-9 } \\
\text { Mean }\end{array}$ & SD & \multicolumn{2}{c}{ Plasma Gal-9 $(\mathrm{pg} / \mathrm{mL})$} \\
& Mean & SD \\
\hline ALF-1 & 42,684 & 532 & 1,634 & 11 \\
ALF-2 & 9,966 & 54 & 419 & 6 \\
ALF-3 & 63,316 & 77 & 565 & 4 \\
ALF-4 & 19,222 & 162 & 819 & 4 \\
ALF-5 & 24,161 & 47 & 757 & 5 \\
ALF-6 & 17,746 & 10 & 646 & 7 \\
ALF-7 & 23,049 & 248 & 1,270 & 2 \\
ALF-8 & 14,445 & 5 & 426 & 1 \\
ALF-9 & 43,411 & 12 & 244 & 6 \\
ALF-10 & 45,958 & 420 & 914 & 10 \\
ALF-11 & 20,346 & 178 & 142 & 5 \\
ALF-12 & 28,589 & 292 & 340 & 2 \\
ALF-13 & 9,071 & 83 & 201 & 18 \\
ALF-14 & 64,392 & 45 & 1,929 & 8 \\
ALF-15 & 49,626 & 494 & 3,047 & 8 \\
ALF-16 & 47,027 & 264 & 778 & 3 \\
ALF-17 & 12,120 & 346 & 312 & 13 \\
ALF-18 & 16,725 & 266 & 249 & 22 \\
ALF-19 & 38,850 & 381 & 300 & 7 \\
ALF-20 & 12,144 & 311 & 270 & 9 \\
ALF-21 & 18,124 & 197 & 360 & 3 \\
ALF-22 & 23,949 & 155 & 640 & 20 \\
ALF-23 & 10,044 & 172 & 252 & 6 \\
\hline
\end{tabular}

truncated forms, Gal-9(N) and Gal-9(C), as well as other degradation products. We suspected that such a degradation might have occurred in the RDS ELISA, which may explain the higher Gal-9 levels observed when compared with the values obtained by GalP ELISA. The GalP ELISA, on the other hand, uses a linker-less artificial form of Gal-9 (Gal-9(0)) that remains highly stable in long-term storage without any changes to protein integrity [32] and allows for reliable quantification. Standard preparations of RDS ELISA and GalP ELISA were compared (Fig. 3B and 3C). Contrary to our hypothesis, the calibration curves generated with both preparations overlapped in both ELISA systems ( $r=1.000, n=8, p<0.0001$; for both comparisons). This excluded the possibility of poor Gal-9 standard in the RDS ELISA. Since both standard preparations were found to produce identical ELISA measurements, Gal-9(0) was used as a common standard, unless otherwise stated, in the subsequent experiments.

The galectin family has 10 members in humans. Even though the amino acid homology among galectins is only $20-35 \%$, we found that polyclonal antibodies against Gal-9 often cross-reacted with other galectins. As several galectins were detected in the serum $[26,27,36,37]$, low specificity could
Table 3. Head-to-head comparison of RDS and GalP ELISAs with HC plasma

\begin{tabular}{lcccc}
\hline & \multicolumn{2}{c}{ RDS ELISA } & \multicolumn{2}{c}{ GalP ELISA } \\
Specimen & $\begin{array}{c}\text { Plasma Gal-9 }(\mathrm{pg} / \mathrm{mL}) \\
\text { Mean }\end{array}$ & SD & $\begin{array}{c}\text { Plasma Gal-9 }(\mathrm{pg} / \mathrm{mL}) \\
\text { Mean }\end{array}$ & SD \\
\hline HC-1 & 6,318 & 53 & 169 & 3 \\
HC-2 & 5,353 & 133 & 101 & 1 \\
HC-3 & 6,512 & 0 & 110 & 2 \\
HC-4 & 4,646 & 44 & 97 & 3 \\
HC-5 & 4,584 & 35 & 60 & 1 \\
HC-6 & 5,239 & 71 & 126 & 1 \\
HC-7 & 4,283 & 142 & 126 & 3 \\
HC-8 & 3,859 & 35 & 85 & 3 \\
HC-9 & 8,051 & 71 & 269 & 1 \\
HC-10 & 6,238 & 9 & 1,037 & 17 \\
HC-11 & 4,434 & 44 & 134 & 5 \\
HC-12 & 5,911 & 88 & 163 & 3 \\
HC-13 & 6,954 & 35 & 140 & 1 \\
HC-14 & 3,478 & 9 & 66 & 1 \\
HC-15 & 8,971 & 407 & 86 & 0 \\
HC-16 & 4,239 & 80 & 78 & 4 \\
HC-17 & 5,495 & 9 & 67 & 8 \\
\hline
\end{tabular}

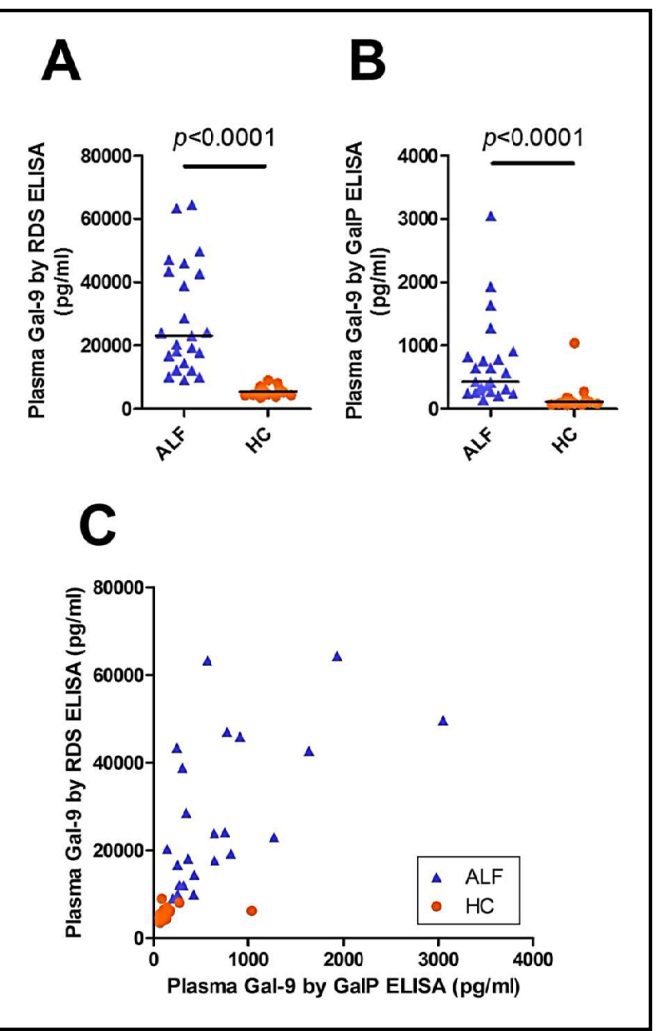

Fig. 2. Comparison between RDS and GalP ELISAs. Gal- 9 concentration measured in plasma from acute liver failure patients (ALF, $n=23$ ) and HC ( $\mathrm{n}=17)$ using ELISAs from RDS (A) and GalP (B). P -value was calculated using the two tailed Mann-Whitney U-test. (C) Correlation between RDS ELISA and GalP ELISA measurements were assessed in ALF and HC independently using the Spearman's coefficient (ALF: $r=0.5632, n=23, p$ $=0.0051$; HC: $r=0.5445, \mathrm{n}=17, \mathrm{p}=0.0238$ ). 


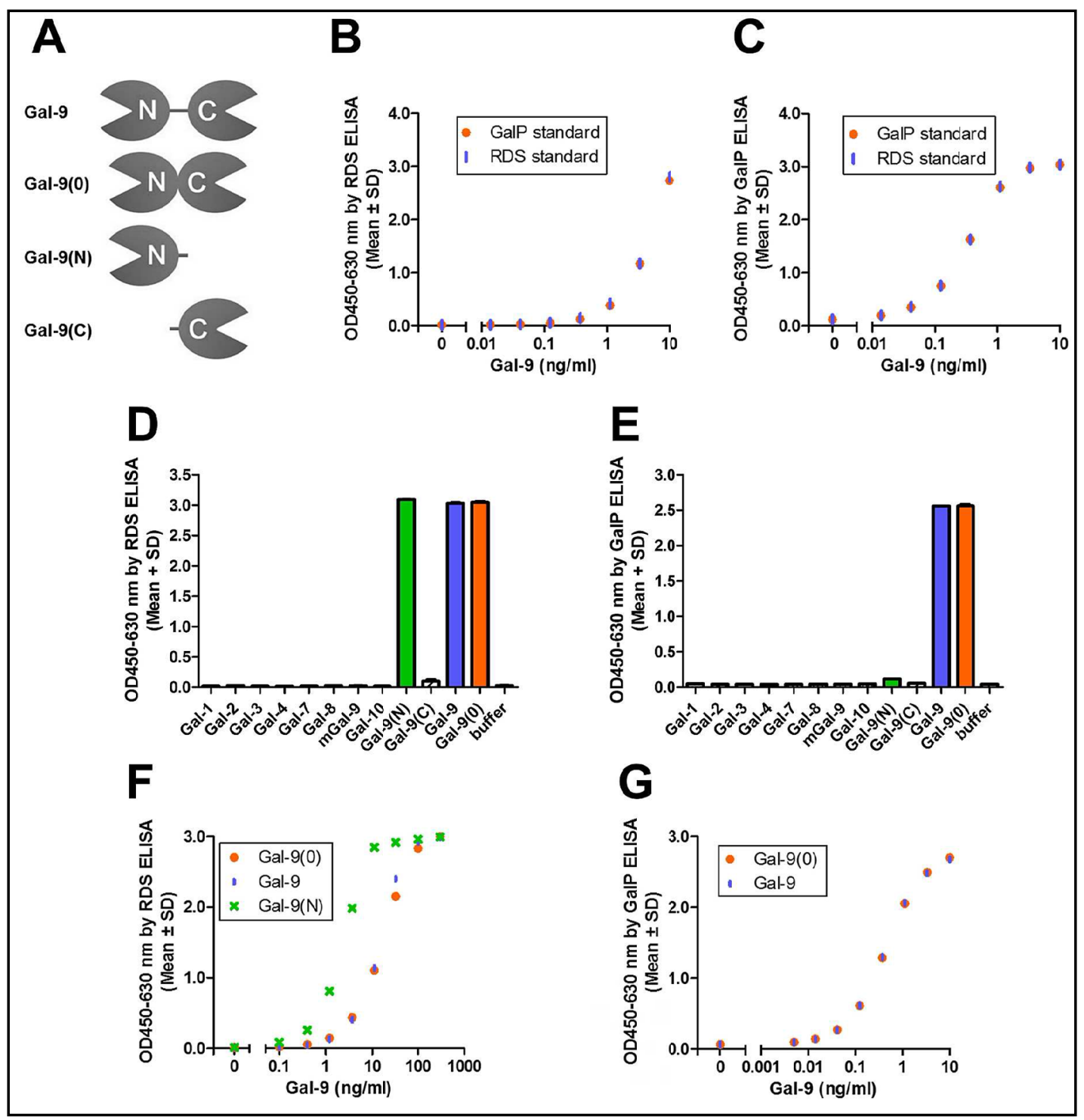

Fig. 3. Characteristics of RDS and GalP ELISAs. (A) Schematic drawing of wild-type Gal-9 (Gal-9), an artificial linker-less Gal-9 (Gal-9(0)), and degradation products of Gal-9 at the linker peptide (Gal-9(N) and Gal-9(C)). Standard Gal-9 preparations from RDS and GalP were compared with the RDS ELISA (B) and GalP ELISA (C). Indicated recombinant galectins were tested for reactivity in RDS ELISA (D, $100 \mathrm{ng} / \mathrm{mL}$ ) and GalP ELISA (E, $10 \mathrm{ng} / \mathrm{mL}$ ). Concentration-dependent curves were generated using the indicated recombinant Gal-9s in RDS ELISA (F) and GalP ELISA (G).

result in falsely enhanced signals. Therefore, a specificity test of each ELISA was performed using a galectin panel with the Gal-9 concentration set to give a maximal signal (100 ng/ $\mathrm{mL}$ for RDS ELISA and $10 \mathrm{ng} / \mathrm{mL}$ for GalP ELISA) (Fig. 3D and 3E). Both ELISA systems were specific against human Gal-9. The GalP ELISA recognized Gal-9 and Gal-9(0), indicating that it detects only full-length Gal-9 as it was designed for detecting only intact Gal-9 using a pair of antibodies that recognize Gal-9(N) and Gal-9(C). The RDS ELISA recognized Gal$9(\mathrm{~N})$, Gal-9, and Gal-9(0); hence, both antibodies used in this sandwich ELISA seemed to recognize epitopes in the Gal-9(N). Therefore, unlike the GalP ELISA, the RDS ELISA can detect degraded Gal-9. If there is more degraded Gal-9 than intact Gal-9 in the blood, it would result in a large difference in the Gal-9 levels obtained with each ELISA; this could explain the observed variations between the GalP and RDS results. 
To further understand variations between the ELISAs, we generated concentrationdependent curves using the proteins recognized by each ELISA (Fig. 3F and 3G). The curves for Gal-9 (MW: 34, 559) and its linker-less form Gal-9(0) (MW: 33, 014) overlapped in both ELISAs. Examination of Gal-9(N) using the RDS ELISA yielded higher reactivity than that observed for Gal-9 or Gal-9(0), with the curve shifted 6-fold lower than that produced by Gal-9 and Gal-9(0). Since the molecular weight of Gal-9(N), which is 18, 193, is about half that of the full-length protein, the molar concentration is about 2-fold higher than full-length Gal-9. This could not account for all of the 6-fold difference. We hypothesized that the RDS ELISA might have higher reactivity against Gal-9(N) than against the intact full-length Gal-9. We considered two possibilities to explain the variation in observed Gal-9 concentrations measured by two ELISA systems. 1) The presence of a large amount of degraded Gal-9 in the blood. 2) Higher reactivity of the RDS ELISA against degraded Gal-9.

\section{Degradation of Gal-9 hinders quantification by RDS ELISA}

Because Gal-9 is known to be digested by elastase in vivo [38], highly purified Gal-9 was incubated with elastase, sampled at the indicated time points by addition into a protease inhibitor cocktail, and then examined by SDS-PAGE with silver staining and ELISA (Fig. $4 \mathrm{~A}$ and $4 \mathrm{~B}$ ). The bands at approximately $33 \mathrm{kDa}$, corresponding to intact Gal-9, gradually decreased over time and almost disappeared by $4 \mathrm{~h}$. Inversely, several bands slightly above $15 \mathrm{kDa}$, corresponding to the degradation products at the linker peptide, increased with time. Even though there are many elastase recognition sites in the protein, digestion seems to occur mainly at the linker peptide at the given incubation time. Measurement with the GalP ELISA correlated well with the gradual degradation of intact Gal-9 observed in the SDS-PAGE gel. Measurement with RDS ELISA, however, indicated an apparent increase in the amount of Gal-9 as the degradation progressed, and reached about 4-fold higher than the original concentration by the end of the incubation. As we hypothesized based on the data in Fig. 3F, the RDS ELISA demonstrated higher reactivity against degraded Gal-9, which distorted the Gal-9 measurement for the test samples.

\section{Detection of plasma Gal-9 by western blotting}

If a large quantity of degradation products exist in the blood, they might be detected by western blotting. However, the high concentration of plasma proteins allows only $0.25 \mu \mathrm{L} /$ well for SDS-PAGE. This indicates, even with the plasma containing the highest concentration of Gal-9 at 64, $392 \mathrm{pg} / \mathrm{mL}$ in an ALF by RDS ELISA assessment $(1,929 \mathrm{pg} / \mathrm{mL}$ by GalP ELISA), that western blotting can process only about $16 \mathrm{pg} /$ well of Gal-9. This quantity is marginal compared to the detection limit with pure Gal-9 and our most sensitive detection

Fig. 4. Aberrant reactivity of RDS ELISA against degraded Gal-9. Wild-type Gal-9 was incubated with elastase and examined at the indicated time by (A) SDS-PAGE with silver staining, and by (B) RDS and GalP ELISAs.

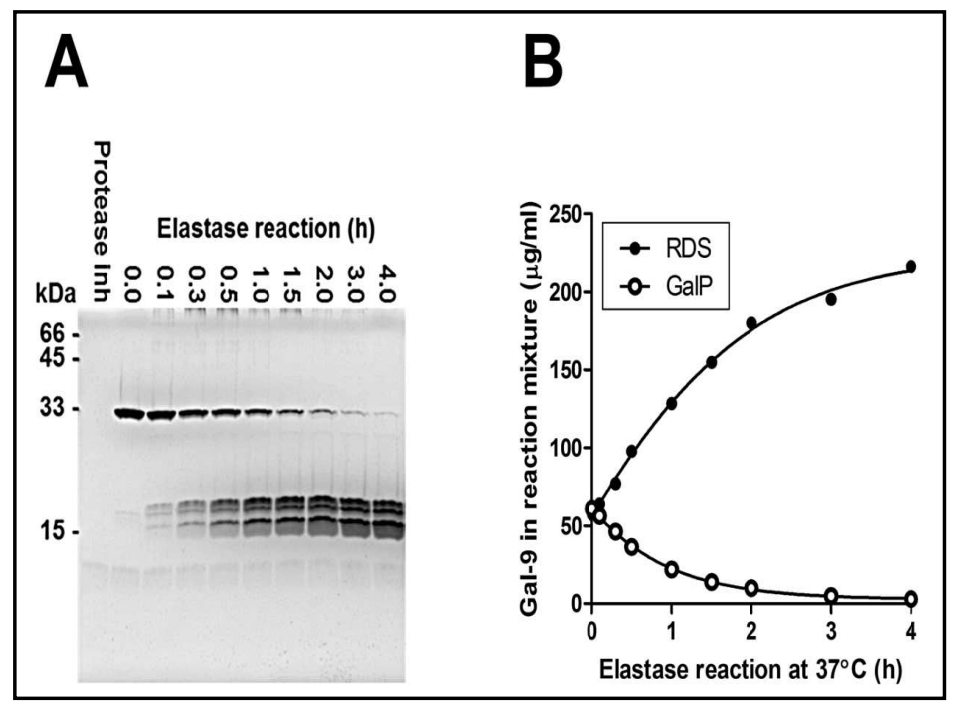




\section{Cellular Physiology Cell Physiol Biochem 2018;50:1856-1868 \begin{tabular}{ll|l} 
and Biochemistry & $\begin{array}{l}\text { DOl: 10.1159/000494866 } \\
\text { Published online: } 3 \text { November } 2018\end{array}$ & $\begin{array}{l}\text { O 2018 The Author(s). Published by S. Karger AG, Basel } \\
\text { www.karger.com/cpb }\end{array}$ \\
\cline { 2 - 3 }
\end{tabular} \\ Niki et al.: Plasma Gal-9 Concentration}

methods, and it is not detectable when the degradation products do not form a single band. Therefore, we purified Gal-9 from the plasma using a spin column containing anti-Gal-9(N) antibody-conjugated beads (Fig. 5A). As RDS does not provide the antibodies from their ELISA separately, we prepared a polyclonal antibody against Gal-9(N) for the purpose. Plasma test samples were collected based on two criteria, sufficient volume to be supplied for purification and a previously established deviation from the correlation between RDS and GalP ELISA measurements (Fig. 5B). Samples A to E are from HC plasma and produced a variable Gal-9 concentration when assessed with a GalP ELISA, but approximately the same concentrations were obtained with the RDS ELISA. Sample A and B derive from the same plasma, but Sample A was supplemented with recombinant Gal-9(0) and Gal-9(N) to act as the positive control for this purification strategy. Samples F through H were from ALF plasma; these samples showed variable Gal-9 concentrations as determined by GalP ELISA, but similar concentrations when subjected to RDS ELISA.

Selected plasma $(150 \mu \mathrm{L})$ was loaded into the column, incubated, and then unbound materials were washed out. Gal-9 in the unbound fraction was measured by both ELISA systems to estimate the amount of Gal-9 left in the column. Finally, Gal-9 was released with small amount of SDS-PAGE sample buffer, then used for SDS-PAGE and subsequent western blotting (Fig. 5C). Signals were observed, in some samples, at the molecular weights corresponding to Gal-9, Gal-9(0), and Gal-9(N), as well as positions lower than Gal-9(N), indicated by Gal-9(deg), with approximate sizes of 12 - $16 \mathrm{kDa}$. These signals were used to determine the quantity of Gal-9 through comparison to a standard constructed with Gal-9(0) and Gal-9(N) (Table 4). There are three isoforms of wild-type Gal-9 differing in the length of the linker peptide and referred to as Large (L), Medium (M), and Small (S) isoforms. The $\mathrm{M}$-isoform is dominant in terms of expression $[39,40]$. In this western blot, we quantified only the M-isoform, because position for the M-isoforms displayed the only clear signal. Fig. 5D and Table 5 summarize the yield in the purification steps where Start and Bound were quantified by RDS ELISA. Eluate represents the total amount of Gal-9, Gal-9(0), Gal-9(N), and Gal-9(deg) determined by western blotting. As mentioned, Sample A was prepared by adding recombinant Gal-9(0) and Gal-9(N) to Sample B, but the high basal level of Sample $\mathrm{B}$, determined by RDS measurement, made the increase caused by the recombinant proteins appear minor (Fig. 5D). More than $96 \%$ of Gal-9 signals were bound to the column in all cases. This indicates that only $10 \%$ of Gal- 9 from the column is enough to produce substantial signals from any samples when western blotting, if the plasma contains a large amount of degraded Gal-9. However, such degradation products were observed only in samples F, G, and $\mathrm{H}$, at far lower amounts than estimated, even though the same antibody was used in the spin column and for western blotting. As this western blotting is for proteins of $11 \mathrm{kDa}$ or more, it is possible that the majority of the degradation products are smaller. However, when HC plasma was filtered with an ultrafiltration devise with the molecular weight cut-off of 10 $\mathrm{kDa}$, no signal was detected in the flow-through fraction by RDS ELISA (Data not shown), which eliminated the possibility of smaller degradation products.

Fig. 5E and Table 6 summarize the purification steps where the GalP ELISA was used for Start and Bound measurement and Eluate is the amount of Gal-9 plus Gal-9(0) that this ELISA can detect. In contrast to the nearly perfect binding to the column determined by the RDS ELISA, the binding determined by GalP was variable with a range of $55 \%$ to $100 \%$ depending on the samples. Elution efficiency in samples A, E, F, and G was $25 \sim 50 \%$. These levels of efficiency are within the expected range for purification. We detected intact Gal-9 in the plasma by western blotting in samples A, E, F, and G, which includes both HC and ALF samples, but these were identified as having high Gal-9 levels by GalP ELISA (Fig. 5B). Additionally, Sample H is from ALF plasma but has low Gal-9 expression, as determined by GalP ELISA. Hence, western blotting did not detect intact Gal-9 in this sample. The GalP ELISA measurements demonstrated a very strong correlation with the existence of intact Gal-9 in the plasma samples (Fig. 5F, $r=0.9132, n=8, p=0.0022$ ). 
A
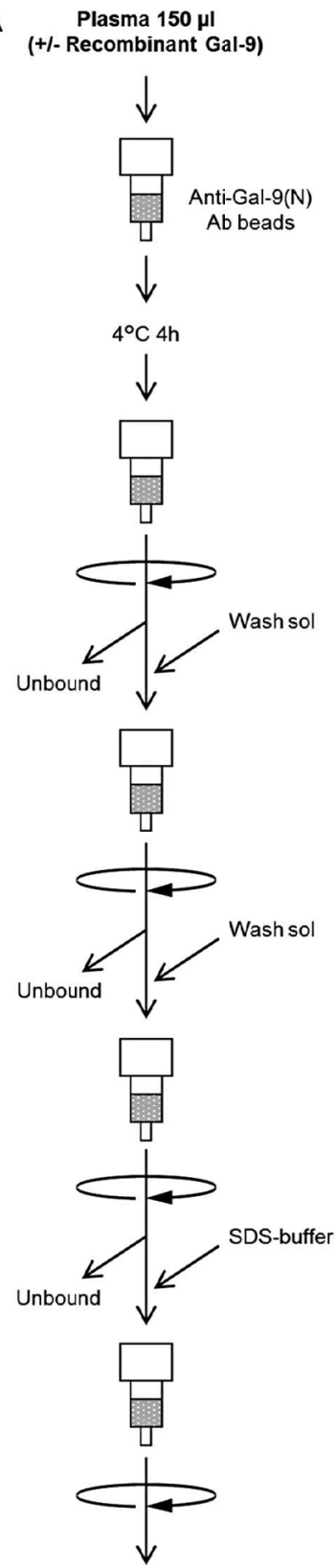

Eluate

\section{B}

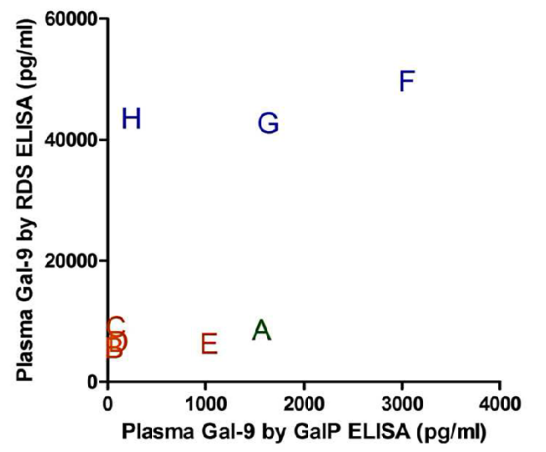

C

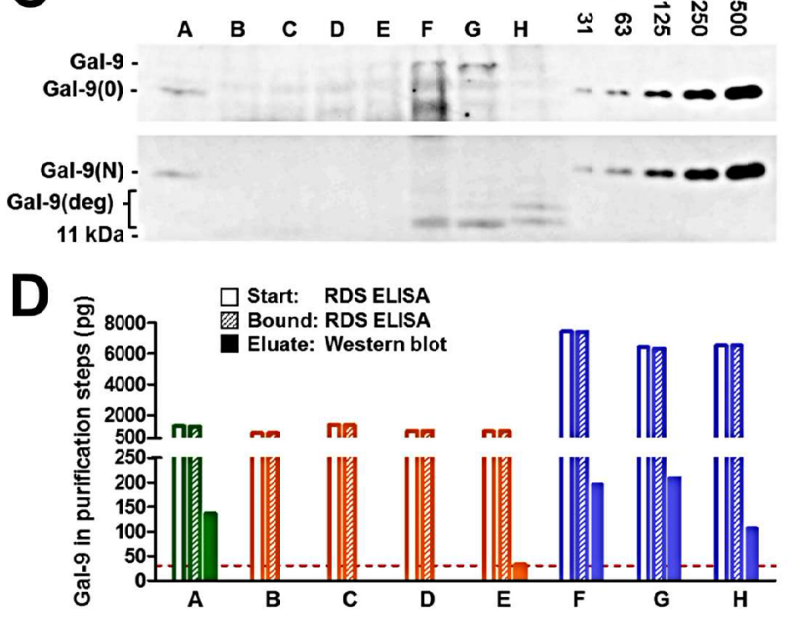

E

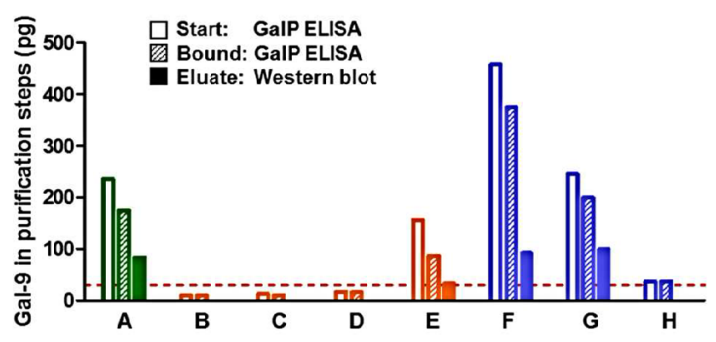

$F$

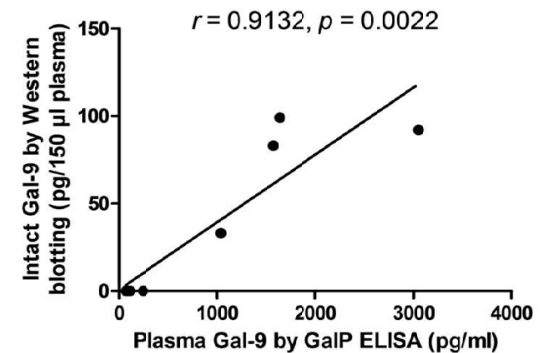

Fig. 5. Detection of plasma Gal-9 by western blotting. (A) Purification scheme to obtain Gal-9 from plasma. (B) Distribution of plasma samples used for purification. Samples A - E are from HC and samples F - H are from ALF. Sample A was prepared by adding Gal-9(0) and Gal-9(N) to sample B. (C) Western blotting for intact Gal-9 (upper) and degraded Gal-9 (lower). (D) Summary of purification yield where Start and Bound was measured by RDS ELISA and Eluate is the sum of Gal-9, Gal-9(0), Gal-9(N), and Gal-9(deg) detected by western blotting. A broken line indicates the detection limit of western blotting. (E) Summary of the purification yield in which Start and Bound were measured by GalP ELISA and Eluate is the sum of Gal-9 and Gal-9(0) detected by western blotting. (F) Correlation between plasma Gal-9 measured by GalP ELISA and intact Gal-9 detected by western blotting. Correlation was assessed with the Spearman's coefficient. 
Table 4. Quantity of Gal-9 species in eluate determined by western blotting. The quantity is expressed in picograms. Gal-9(deg) represents bands smaller than Gal-9(N), with an approximate size of $12-16 \mathrm{kDa}$

\begin{tabular}{lcccccccc}
\hline Gal-9s & & \multicolumn{7}{c}{ Sample } \\
& A & B & C & D & E & F & G & H \\
\hline Gal-9 & 0 & 0 & 0 & 0 & 33 & 92 & 99 & 0 \\
Gal-9(0) & 83 & 0 & 0 & 0 & 0 & 0 & 0 & 0 \\
Gal-9(N) & 52 & 0 & 0 & 0 & 0 & 0 & 0 & 0 \\
Gal-9(deg) & 0 & 0 & 0 & 0 & 0 & 104 & 111 & 106 \\
Total & 136 & 0 & 0 & 0 & 33 & 196 & 209 & 106 \\
\hline
\end{tabular}

Table 5. Quantity of Gal-9 in each fraction determined by RDS ELISA. Both A and B are based on HC-17 plasma, but only A was supplemented with recombinant Gal-9(0) and Gal-9(N) (225 pg each) to act as positive control. The starting material for Sample A contains 1274 pg of Gal-9 (824 pg out of HC-17 + 225 pg of Gal-9(0) +225 pg of Gal-9(N)). The amount of Bound Gal-9 was calculated by subtracting the Unbound Gal-9 measured by ELISA from the Start

\begin{tabular}{lcccccccc}
\hline Fraction & \multicolumn{7}{c}{ Sample } \\
& A & B & C & D & E & F & G & H \\
\hline Plasma & HC-17 & HC-17 & HC-15 & HC-3 & HC-10 & ALF-15 & ALF-1 & ALF-9 \\
Additive & Gal-9(0) Gal-9 (N) & & & & & & & \\
Start & 1,274 & 824 & 1,346 & 977 & 936 & 7,444 & 6,403 & 6,512 \\
Unbound & 49 & 0 & 0 & 0 & 0 & 28 & 83 & 0 \\
Bound & 1,225 & 824 & 1,346 & 977 & 936 & 7,416 & 6,320 & 6,512 \\
\hline
\end{tabular}

Table 6. Quantity of Gal-9 in each fraction determined by GalP ELISA. The same fractions in Table 5. were measured. Since GalP ELISA does not react with truncated Gal-9, the starting material for Sample A contains $235 \mathrm{pg}$ of Gal-9 (10 pg out of HC-17+225 pg of Gal-9(0)) that is measurable with this ELISA

\begin{tabular}{lcccccccc}
\hline Fraction & \multicolumn{8}{c}{ Sample } \\
& A & B & C & D & E & F & G & H \\
\hline Plasma & HC-17 & HC-17 & HC-15 & HC-3 & HC-10 & ALF-15 & ALF-1 & ALF-9 \\
Additive & Gal-9(0) Gal-9 (N) & & & & & & & \\
Start & 235 & 10 & 13 & 17 & 156 & 457 & 245 & 37 \\
Unbound & 60 & 0 & 2 & 0 & 70 & 83 & 46 & 0 \\
Bound & 175 & 10 & 10 & 16 & 86 & 374 & 199 & 37 \\
\hline
\end{tabular}

\section{Discussion}

Numerous studies have been published on the correlation between Gal-9 concentration in the blood and various pathological conditions. These studies show large differences in the Gal-9 concentrations, even in the healthy control groups, and those differences could be attributed to the choice of ELISA products. By a direct comparison, with the same plasma samples, we confirmed that the RDS ELISA quantifies an approximately 50 -fold higher median Gal-9 concentration than that determined with the GalP ELISA. We proposed two hypotheses to explain the variation between these measurements. 1) The RDS ELISA has higher reactivity against degraded Gal-9. 2) There is significantly more degraded Gal9 in the plasma. The $1^{\text {st }}$ hypothesis was confirmed through Gal-9 digestion with elastase, 


\section{Cellular Physiology Cell Physiol Biochem 2018;50:1856-1868

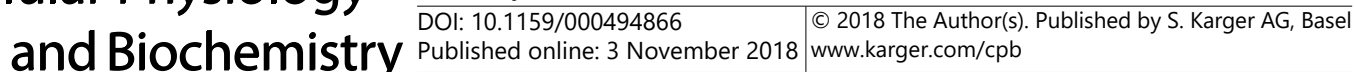 \\ Niki et al.: Plasma Gal-9 Concentration}

where complete digestion at the linker peptide falsely increased the quantification 4-fold. To examine the $2^{\text {nd }}$ hypothesis, we concentrated Gal-9 in the plasma using an anti-Gal-9(N) antibody column and tried detecting degraded Gal-9 by western blotting. There was a small quantity of degraded Gal-9 with a size smaller than the products of elastase digestion. We conclude that these small quantities of degradation products in the blood are the causative of the approximately 50-fold higher estimation of Gal-9 in blood determined by RDS ELISA. Blood born degraded Gal-9 likely has a higher reactivity than the products of elastase digestion when measured by RDS ELISA.

The aberrant results from RDS ELISA may be the product of antibodies that bind strongly against degraded or denatured Gal-9. Antibodies of this kind are sometimes generated when a peptide antigen is used in place of whole protein for immunization. Degradation may expose epitopes against these antibodies or destroy the tertiary structure that the epitopes are incorporated into when Gal-9 is intact enough. This degradation allows these antibodies to bind, and results in higher signals that are falsely translated into a higher estimated Gal-9 concentration. It is likely that human specimens of any kinds will contain degraded Gal-9, which would distort the quantification by RDS ELISA, hence the kit has little value for quantification of Gal-9 in test samples. On the contrary, the GalP ELISA measurements correlated well with the amount of intact Gal-9 in the plasma (Fig. 5F), which confirmed the reliability of the system. Using the GalP ELISA we measured 23 ALF (Table 2) and 17 HC (Table 3) samples and obtained medians $\left(25^{\text {th }}-75^{\text {th }}\right.$ percentiles $)$ of $426 \mathrm{pg} / \mathrm{ml}(285-799 \mathrm{pg} /$ $\mathrm{mL}$ ) and $110 \mathrm{pg} / \mathrm{mL}(67-154 \mathrm{pg} / \mathrm{mL}$ ) respectively. This concentration is close to the expected Gal-9 concentration in the current cohort. The generalization of normal Gal-9 values beyond the current study will require the accumulation of more data, as Gal-9 assessment vary significantly depending on the country [Unpublished data]. Differences such as race, dietary habits, and unrecognized infections might change the Gal-9 expression in the blood, which should be examined in the future.

\section{Acknowledgements}

This research was supported by the Japan Society for the Promotion of Science (JSPS) Grants-in-Aid for Scientific Research (KAKENHI), Grant Number JP17H01690 and JP16K08320.

\section{Disclosure Statement}

Drs. Niki and Hirashima are board members of GalPharma Co., Ltd. However, the research in this report is purely scientific and is not influenced by the company's commercial activities.

\section{References}

-1 Wiersma VR, de Bruyn M, Helfrich W, Bremer E: Therapeutic potential of Galectin-9 in human disease. Med Res Rev DOI:10.1002/med.20249.

2 Anderson AC, Joller N, Kuchroo VK: Lag-3, Tim-3, and TIGIT: Co-inhibitory Receptors with Specialized Functions in Immune Regulation. Immunity 2016;44:989-1004.

-3 Wiersma VR, de Bruyn M, Wei Y, van Ginkel RJ, Hirashima M, Niki T, Nishi N, Zhou J, Pouwels SD, Samplonius DF, Nijman HW, Eggleton P, Helfrich W, Bremer E: The epithelial polarity regulator LGALS9/ galectin-9 induces fatal frustrated autophagy in KRAS mutant colon carcinoma that depends on elevated basal autophagic flux. Autophagy 2015;11:1373-1388. 


\section{Cellular Physiology Cell Physiol Biochem 2018;50:1856-1868 and Biochemistry \begin{tabular}{c|c|c|c|} 
DOI: 10.1159/000494866 \\
Published 2018 The Author(s). Published by S. Karger AG, Basel
\end{tabular}

-4 Nobumoto A, Oomizu S, Arikawa T, Katoh S, Nagahara K, Miyake M, Nishi N, Takeshita K, Niki T, Yamauchi A, Hirashima M: Galectin-9 expands unique macrophages exhibiting plasmacytoid dendritic cell-like phenotypes that activate NK cells in tumor-bearing mice. Clin Immunol 2009;130:322-330.

5 Kadowaki T, Arikawa T, Shinonaga R, Oomizu S, Inagawa H, Soma G, Niki T, Hirashima M: Galectin-9 signaling prolongs survival in murine lung-cancer by inducing macrophages to differentiate into plasmacytoid dendritic cell-like macrophages. Clin Immunol 2012;142:296-307.

-6 Nagahara K, Arikawa T, Oomizu S, Kontani K, Nobumoto A, Tateno H, Watanabe K, Niki T, Katoh S, Miyake M, Nagahata S, Hirabayashi J, Kuchroo VK, Yamauchi A, Hirashima M: Galectin-9 increases Tim-3+ dendritic cells and CD8+ T cells and enhances antitumor immunity via galectin-9-Tim-3 interactions. J Immunol 2008;181:7660-7669.

7 Wang K, Chen Z, Wu R, Yin J, Fan M, Xu X: Prognostic Role of High Gal-9 Expression in Solid Tumours: a Meta-Analysis. Cell Physiol Biochem 2018;45:993-1002.

-8 Fujita K, Niki T, Nomura T, Oura K, Tadokoro T, Sakamoto T, Tani J, Yoneyama H, Morishita A, Kuroda N, Arai T, Nishimoto N, Himoto T, Hirashima M, Masaki T: Correlation between serum galectin-9 levels and liver fibrosis. J Gastroenterol Hepatol 2018;33:492-499.

-9 Mengshol JA, Golden-Mason L, Arikawa T, Smith M, Niki T, McWilliams R, Randall JA, McMahan R, Zimmerman MA, Rangachari M, Dobrinskikh E, Busson P, Polyak SJ, Hirashima M, Rosen HR: A crucial role for Kupffer cell-derived galectin-9 in regulation of $\mathrm{T}$ cell immunity in hepatitis $\mathrm{C}$ infection. PLoS One 2010;5:e9504.

10 Saitoh H, Ashino Y, Chagan-Yasutan H, Niki T, Hirashima M, Hattori T: Rapid decrease of plasma galectin-9 levels in patients with acute HIV infection after therapy. Tohoku J Exp Med 2012;228:157-161.

11 Chagan-Yasutan H, Ndhlovu LC, Lacuesta TL, Kubo T, Leano PS, Niki T, Oguma S, Morita K, Chew GM, Barbour JD, Telan EF, Hirashima M, Hattori T, Dimaano EM: Galectin-9 plasma levels reflect adverse hematological and immunological features in acute dengue virus infection. J Clin Virol 2013;58:635-640.

-12 Tandon R, Chew GM, Byron MM, Borrow P, Niki T, Hirashima M, Barbour JD, Norris PJ, Lanteri MC, Martin JN, Deeks SG, Ndhlovu LC: Galectin-9 is rapidly released during acute HIV-1 infection and remains sustained at high levels despite viral suppression even in elite controllers. AIDS Res Hum Retroviruses 2014;30:654-664.

13 Katoh S, Ikeda M, Shimizu H, Mouri K, Obase Y, Kobashi Y, Fukushima K, Hirashima M, Oka M: Increased levels of plasma galectin-9 in patients with influenza virus infection. Tohoku J Exp Med 2014;232:263-267.

14 Rosen HR, Biggins SW, Niki T, Gralla J, Hillman H, Hirashima M, Schilsky M, Lee WM: Acute Liver Failure Study Group: Association between plasma level of galectin-9 and survival of patients with drug-induced acute liver failure. Clin Gastroenterol Hepatol 2016;14:606-612.

15 Dembele BP, Chagan-Yasutan H, Niki T, Ashino Y, Tangpukdee N, Shinichi E, Krudsood S, Kano S, Hattori T: Plasma levels of Galectin-9 reflect disease severity in malaria infection. Malar J 2016;15:403.

16 Nishio A, Tatsumi T, Nawa T, Suda T, Yoshioka T, Onishi Y, Aono S, Shigekawa M, Hikita H, Sakamori R, Okuzaki D, Fukuhara T, Matsuura Y, Hiramatsu N, Takehara T: CD14+ monocyte-derived galectin-9 induces natural killer cell cytotoxicity in chronic hepatitis C. Hepatology 2017;65:18-31.

-17 Shiratori B, Zhao J, Okumura M, Chagan-Yasutan H, Yanai H, Mizuno K, Yoshiyama T, Idei T, Ashino Y9 Nakajima C, Suzuki Y, Hattori T: Immunological roles of elevated plasma levels of matricellular proteins in Japanese patients with pulmonary tuberculosis. Int J Mol Sci 2016;18:E19.

18 Jost S, Moreno-Nieves UY, Garcia-Beltran WF, Rands K, Reardon J, Toth I, Piechocka-Trocha A, Altfeld M, Addo MM: Dysregulated Tim-3 expression on natural killer cells is associated with increased Galectin-9 levels in HIV-1 infection. Retrovirology 2013;10:74.

19 Brubel R, Bokor A, Pohl A, Schilli GK, Szereday L, Bacher-Szamuel R, Rigo J Jr, Polgar B: Serum galectin-9 as a noninvasive biomarker for the detection of endometriosis and pelvic pain or infertility-related gynecologic disorders. Fertil Steril 2017;108:1016-1025.

20 Meggyes M, Miko E, Polgar B, Bogar B, Farkas B, Illes Z, Szereday L: eCollection 2014. Peripheral blood TIM3 positive NK and CD8+ T cells throughout pregnancy: TIM-3/galectin-9 interaction and its possible role during pregnancy. PLoS One 2014;9:e92371.

21 Wu M, Zhu Y, Zhao J, Ai H, Gong Q Zhang J, Zhao J, Wang Q La X, Ding J: Soluble costimulatory molecule sTim3 regulates the differentiation of Th1 and Th2 in patients with unexplained recurrent spontaneous abortion. Int J Clin Exp Med 2015;8:8812-8819. 


\section{Cellular Physiology Cell Physiol Biochem 2018;50:1856-1868 and Biochemistry DOI: 10.1159/000494866 2018 (O) 2018 The Author(s). Published by S. Karger AG, Basel

-22 Kikushige Y1, Miyamoto T, Yuda J, Jabbarzadeh-Tabrizi S, Shima T, Takayanagi S, Niiro H, Yurino A, Miyawaki K, Takenaka K, Iwasaki H, Akashi K: A TIM-3/Gal-9 autocrine stimulatory loop drives self-renewal of human myeloid leukemia stem cells and leukemic progression. Cell Stem Cell 2015;17:341-352.

23 Bellutti Enders F1, van Wijk F, Scholman R, Hofer M, Prakken BJ, van Royen-Kerkhof A, de Jager W: Correlation of CXCL10, tumor necrosis factor receptor type II, and galectin 9 with disease activity in juvenile dermatomyositis. Arthritis Rheumatol 2014;66:2281-2289.

24 Nakajima R, Miyagaki T, Oka T, Nakao M, Kawaguchi M, Suga H, Morimura S, Kai H, Asano Y, Tada Y, Kadono T, Sato S, Sugaya M: Elevated serum galectin-9 levels in patients with atopic dermatitis. J Dermatol 2015;42:723-726.

25 Zhu R, Liu C, Tang H, Zeng Q Wang X, Zhu Z, Liu Y, Mao X, Zhong Y: Serum galectin-9 levels are associated with coronary artery disease in Chinese individuals. Mediators Inflamm 2015;2015:457167.

26 Liu KT, Liu YH, Chen YH, Lin CY, Huang CH, Yen MC, Kuo PL: Serum galectin-9 and galectin-3-binding protein in acute dengue virus infection. Int J Mol Sci 2016;17:E832.

27 He XW, Li WL, Li C, Liu P, Shen YG, Zhu M, Jin XP: Serum levels of galectin-1, galectin-3, and galectin-9 are associated with large artery atherosclerotic stroke. Sci Rep 2017;7:40994.

28 Feng X, Feng J: Clinical significance of Tim3-positive T cell subsets in patients with multiple sclerosis. J Clin Neurosci 2016;34:193-197.

-29 Saigusa R, Asano Y, Nakamura K, Hirabayashi M, Miura S, Yamashita T, Taniguchi T, Ichimura Y, Takahashi T, Yoshizaki A, Miyagaki T, Sugaya M, Sato S: Systemic sclerosis dermal fibroblasts suppress Th1 cytokine production via galectin-9 overproduction due to Fli1 deficiency. J Invest Dermatol 2017;137:1850-1859.

-30 Kurose Y, Wada J, Kanzaki M, Teshigawara S, Nakatsuka A, Murakami K, Inoue K, Terami T, Katayama A, Watanabe M, Higuchi C, Eguchi J, Miyatake N, Makino H: Serum galectin-9 levels are elevated in the patients with type 2 diabetes and chronic kidney disease. BMC Nephrol 2013;14:23.

-31 de Kivit S, Saeland E, Kraneveld AD, van de Kant HJ, Schouten B, van Esch BC, Knol J, Sprikkelman AB, van der Aa LB, Knippels LM, Garssen J, van Kooyk Y, Willemsen LE: Galectin-9 induced by dietary synbiotics is involved in suppression of allergic symptoms in mice and humans. Allergy 2012;67:343-352.

-32 Nishi N, Itoh A, Fujiyama A, Yoshida N, Araya S, Hirashima M, Shoji H, Nakamura T: Development of highly stable galectins: truncation of the linker peptide confers protease-resistance on tandem-repeat type galectins. FEBS Lett 2005;579:2058-2064.

33 Niki T, Tsutsui S, Hirose S, Aradono S, Sugimoto Y, Takeshita K, Nishi N, Hirashima M: Galectin-9 is a high affinity IgE-binding lectin with anti-allergic effect by blocking IgE-antigen complex formation. J Biol Chem 2009;284:32344-32352.

34 Matsushita N, Nishi N, Seki M, Matsumoto R, Kuwabara I, Liu FT, Hata Y, Nakamura T, Hirashima M: Requirement of divalent galactoside-binding activity of ecalectin/galectin- 9 for eosinophil chemoattraction. J Biol Chem 2000;275:8355-8360.

-35 Nobumoto A1, Nagahara K, Oomizu S, Katoh S, Nishi N, Takeshita K, Niki T, Tominaga A, Yamauchi A, Hirashima M: Galectin-9 suppresses tumor metastasis by blocking adhesion to endothelium and extracellular matrices. Glycobiology 2008;18:735-744.

-36 Barrow H, Guo X, Wandall HH, Pedersen JW, Fu B, Zhao Q, Chen C, Rhodes JM, Yu LG: Serum galectin-2, -4, and -8 are greatly increased in colon and breast cancer patients and promote cancer cell adhesion to blood vascular endothelium. Clin Cancer Res 2011;17:7035-7046.

-37 Cho SB, Kim JS, Zheng Z, Choi MJ, Choi IG, Oh HS, Ahn KJ: Decreased tissue and serum expression of galectin-7 in patients with hypertrophic scars. Acta Derm Venereol 2013;93:669-673.

-38 Vega-Carrascal I, Reeves EP, Niki T, Arikawa T, McNally P, O’Neill SJ, Hirashima M, McElvaney NG: Dysregulation of TIM-3-galectin-9 pathway in the cystic fibrosis airways. J Immunol 2011;186:2897-2909.

-39 Heusschen R, Schulkens IA, van Beijnum J, Griffioen AW, Thijssen VL: Endothelial LGALS9 splice variant expression in endothelial cell biology and angiogenesis. Biochim Biophys Acta 2014;1842:284-292.

40 Chabot S1, Kashio Y, Seki M, Shirato Y, Nakamura K, Nishi N, Nakamura T, Matsumoto R, Hirashima M: Regulation of galectin-9 expression and release in Jurkat T cell line cells. Glycobiology 2002;12:111-118. 